\title{
Thematic Symposium: The Impact of Technology on Ethics, Professionalism and Judgement in Accounting
}

\author{
Sally Gunz ${ }^{1} \cdot$ Linda Thorne ${ }^{2}$
}

Published online: 1 January 2020

(c) Springer Nature B.V. 2020

The call for this Thematic Symposium was ambitious and sweeping and deliberatively so. It acknowledged the historic bifurcation within the academic research of accounting decision making, the focus of which generally took one of two forms (Gaa and Thorne 2004); the technical and the ethical/ professional. While there are obvious reasons for this to be the case, the extraordinary growth in the application and role of technology in replacing basic accounting functions, makes it particularly pressing for academic energy to focus on basic questions that arise out of the interaction between the two components.

Accountants and auditors have increased the use of technology in decision making in an effort to standardize and control the flow of information in the firm, as a response to the increased globalization of their clients, and, at times, to affect cost savings through the use of off-shore employees. Technology was initially adopted in order to enhance the effectiveness and accuracy of accounting decision making. While forecasts may well be exaggerated, some reports in the media and by PWC have suggested that by 2030 between 40 and $90 \%$ of all accounting functions will be replaced by technology (PWC 2017; Maney 2016).

Technology has undoubted benefits but also consequences. Of particular concern to those who address ethical considerations in the workplace is what has become known as a responsibility gap; that is, the extent to which or the possibility that the adoption of technology will lead to the abdication of ethical responsibility for the consequences of decisions by real people, and here, accountants and taxpayers.

Linda Thorne

lthorne@schulich.yorku.ca

Sally Gunz

sgunz@uwaterloo.ca

1 School of Accounting and Finance, University of Waterloo, Waterloo, Canada

2 Schulich School of Business, York University, Toronto, Canada
More specifically, Johnson (2015) suggests that technology actually encourages the abdication of responsibility because there is a failure to trigger the ethical concerns involved in the decision. He argues this occurs because of several factors. Most notably technology is treated as if it has an immutable authority.

Ignoring a technology induced responsibility gap is problematic because the information relied upon by accounting professionals depends upon the integrity of the data input used to formulate actual decisions and audit opinions (PWC 2017). The responsibility gap draws attention to the question of who is responsible for the integrity of the data as well as the decisions formulated by technological means. It further raises the importance of whether and how ethical/ professional considerations are to be integrated in devising what appear to be purely technical processes. If they are not, should they be and, if so, how should they be? Many have considered the adoption of technology to be a panacea to the issues of addressing vast amounts of data efficiently and effectively. However, the fundamental questions of how and to what extent technology influences ethical decision making in the accounting domain and on the ethical decisions of professional accountants, must be paramount.

The early literature on the use of technology in the accounting domain highlights the benefits associated with the adoption of technology as the quality of technical decision making increases with technological integration. Established technological systems used by accounting firms help routinize decision making by providing greater access to individuals with specialized knowledge (Nelson and Tan 2005), replacing mundane repetitive tasks, and facilitating the examination of greater quantities of data. Thus, prior literature suggests that when accountants adopt technology, decision outcomes tend to coalesce, and technical quality increases as higher levels of accuracy are obtained.

A recent review (Moll and Yigitbasioglu 2019) of 38 papers exploring how accountants and the accounting profession have been influenced by the adoption of technology 
confirms the above. The focus of scholars and of the accounting profession has been on the technical impact of the adoption of technology. However, the review highlights that there has been very little, if any, exploration of how technology will influence the ethical aspect of accounting. Ignoring the ethical aspects of technological adoption in the accounting context is particularly alarming given that the key competitive advantage of the accounting profession is the exercise of professional judgment and its inherent ethical duty to protect the public interest. Yet the interpretive and intuitive nature of ethical reasoning can be crowded out when accountants rely on technology in arriving at professional judgment. Thus, today it is critical to understand the influence that technology has on the ethical aspect of the accounting context and how individuals, and in particular, professional accountants, respond to technology.

The goal of the Thematic Symposium was to bring attention to the need to advance our understanding of how to help business ethics as a field think systematically about the full influence of technology on all aspects of the accounting profession and its practice. The Thematic Symposium sought to understand and highlight the ethical consequences of technology on the accounting profession, accounting professionalism and recipients and users of all accounting services. With this in mind we have three papers that consider different aspects of the interface of technology on the ethical aspect of decisions in the accounting domain. Two of the papers consider how technology influences individuals' tendency to report honestly, and, not surprisingly, they are both situated in the tax context. The first paper considers, "Selfish Sharing? The Impact of the Sharing Economy on Tax Reporting Honesty" by Leslie Berger, Lan Guo and Tisha King. The second paper is "Are individuals more willing to lie to a computer or a human? Evidence from a Tax Compliance Setting" by Ethan LaMothe and Donna Bobek. Our third and final paper is a very intriguing exploration of the "Implications of Using Artificial Intelligence on Auditing" by Ivy Munoko, Helen Brown-Liburd and Miklos Vasarhelyi. Each is now explored in turn.

The first two papers are grounded in a tax setting and consider the interface between technology and the human tendency to report more or less honestly. The findings of both papers suggest that technology encourages dishonest reporting. The lack of social interface resulting from the adoption of technology dampens ethical considerations when reporting.

The first paper (Berger et al. 2020) considers the use of peer-to-peer (P2P) platforms and their effect on the honesty of tax reporting. The technological innovation of the sharing economy includes the adoption of P2P platforms in order to transform the delivery of goods and services through the sharing of, for example, transportation or shelter. The authors use a large number (746) of taxpayers in an experiment and show that taxpayers are more likely to dishonestly report when the prosocial values are incongruent with their personal values than when these values are congruent or when only economic benefits are highlighted by the platform. In addition, consistent with moral licensing, they also find that taxpayers' guilt towards misreporting mediates the relationship between value-incongruent prosocial sharing and tax reporting honesty.

Our second paper (LaMothe and Bobek 2020) explores the influence of technology adoption on ethical decision making by examining the interface between taxpayers' tendency to honestly report and the use of tax software. With the widespread adoption of pre-packaged tax software for a range of complexity of tax return, the use of the interface between technology and individuals is extremely relatable and offers a practical setting. The authors compare how the preparation method, tax software versus a human tax professional, influences taxpayers' willingness to lie. They find that individuals are more willing to lie to tax software than to a human tax professional. Those same individuals also believe that tax software is less likely to detect their cheating than the human preparer. The results from this study suggest individuals who use tax software are more willing to lie about their taxes than those using a human tax professional. The paper shows the importance of social presence and the perceived detectability of the lie, which suggests that software has less of a social presence than a human which also appears to lead to the belief that software is less likely to detect cheating than a human. Beyond the practical implications for tax enforcement, both of these papers highlight how technology impacts individuals' ethicality and suggests that social factors (or lack thereof) explain why individuals interact differently with computers versus humans.

Our third paper addresses broader and more fundamental issues as it considers the adoption of Artificial Intelligence (AI) in audit and advisory functions. AI encompasses the adoption of technology in order to solve problems and then to learn as it does so. Already some accounting firms have started to adopt Artificial Intelligence (AI) and they equate the benefits of its speed and accuracy to the adoption of other technologies. However, the ethical implications associated with the adoption of AI go beyond those of other technologies. It not only depends upon pre-programmed algorithms and protecting those algorithms (Nichols 2019), but it also embraces the actual decision making and judgements that can go beyond pre-existing constraints through adaptation and learning. Thus, AI takes several steps beyond efficient processing of routinized tasks in that it can in fact encroach on decisions that traditionally have been limited to the professional judgment of accountants. As the authors point out, it is paramount that the accounting profession becomes aware of unintended consequences that may emerge from the use of $\mathrm{AI}$ in the accounting and audit functions. This is 
particularly relevant to the accounting and audit judgment context as typically here ethical decisions involve tradeoffs between different options, neither of which is absolutely ethically acceptable. How does a machine handle a problem that is outside its programmed constraints? How does AI then resolve the ethical dilemmas it encounters when they were not envisioned in the original algorithms? Most importantly, who is ultimately responsible for the decisions made by AI?

Munoko et al. (2020) explore these issues. Not only do they attempt to forecast the ethical implications of the use of $\mathrm{AI}$ in audit, but they also develop an analysis of the practical ethical and social issues surrounding AI. In addition, they explore the complex accountability for the policy and governance associated with $\mathrm{AI}$, as well as the implications of the further adoption of AI for the audit function and the auditing profession. They conclude that AI cannot completely replace the ethical aspects of professional accountants' judgment. Further, much work needs to be done in order to establish the parameters, the responsibility and the accountability associated with the technological advancements and professional accountants' reliance on AI.

Research on the impact of technology on the ethical aspects of professional judgement not only has implications for accounting itself and the accounting profession, it also has broad implications for society. It is the professional accountants' role and responsibility, guided by scholarly research, to provide a clear understanding of how to maintain the ethicality of their professional judgment in the face of encroaching technology. The papers in the symposium take a first step toward understanding how technology can detrimentally impact ethical decision making that, in turn, will lead scholars to consider how to overcome the reductions in ethical decision quality that can inadvertently follow from the adoption of technology. By eliminating social interaction and assuming the role of authority, technology has the potential to erode accountability and the quality of decision outcomes by detrimentally influencing the ethical aspect of decisions even in the face of technical accuracy. Importantly, the papers in this symposium lead us to ponder the more important questions of who is responsible for decisions, and how are ethical/professional responsibilities highlighted in devising the service of purely technical applications. How do we ensure that ethical and professional responsibilities are not overlooked, and how and when does this need to happen?

The adoption of technology as a replacement for routine tasks, as decision support, and the use of $\mathrm{AI}$ in the audit, tax and the management accounting arenas may replace some of the professional and ethical aspects of the professional accountants' role. This is a moral and professional concern. The question remains to what extent will AI be able to grasp complexities better than that of professional accountants? In what situations will professional accountants be able to grasp complexities better than AI? Who will have the wisdom to know the difference? Additional insight is needed into the boundaries and the accountability that may be/ should be / could be developed in the use of AI, in the exploration of the benefits of $\mathrm{AI}$, and in considering the ethical implications of the use of this emerging technology particularly in the context of the audit and the attest function.

When professional accountants accede the ethical aspect of their professional judgment to a machine, they must consider what is their own morality versus what is the morality of a machine. Does morality extend from the programmer who wrote the initiate algorithm, or are ethical concerns to be overlooked assuming of course that machines cannot be programmed to recognize complex ethical dilemmas? Are we, as the ethical guardians of the public trust, prepared to adopt technology without explicit consideration of the impact on ethical decision making? Who is accountable for the decision outcomes of machines? The papers in this symposium show that individuals react differently when technology is employed, and the ethicality of their decision making suffers in the absence of social interaction. Given these findings, how can we learn, anticipate and adapt our ethical decision process with this sea change associated with the adoption of technology? These papers should encourage further interest and research as they help us, both as ethical researchers and members of the accounting profession, contemplate and consider not only what are the ethical dilemmas and challenges we face with the increasing adoption of new and more advanced technology, but also how they should be addressed and resolved. Nevertheless, the journey has only begun.

\section{References}

Gaa, J. C., \& Thorne, L. (2004). An introduction to the special issue on professionalism and ethics in accounting education. Issues in Accounting Education, 19(1), 1-7.

Johnson, D. G. (2015). Technology with no human responsibility? Journal of Business Ethics, 127(4), 707-719.

Maney, K. (2016). How artificial intelligence and robots will radically transform the economy. New York City: Newsweek.

Moll, J., \& Yigitbasioglu, O. (2019). The role of internet-related technologies in shaping the work of accountants: New directions for accounting research. The British Accounting Review. https://doi. org/10.1016/j.bar.2019.04.002.

Nelson, M., \& Tan, H. T. (2005). Judgment and decision-making research in auditing: A task, person, and interpersonal interaction perspective. Auditing, 24, 41-71.

Nichols, P. (2019). Bribing the machine: Protecting the integrity of algorithms as the revolution begins. American Business Law Journal, 56(4), 771-814.

PWC UK (2017) Automation, PWC Report UKEC March Volume 2, Section 4.

Publisher's Note Springer Nature remains neutral with regard to jurisdictional claims in published maps and institutional affiliations. 